\section{Effekter av cannabis varer lenger enn antatt}

KRONIKK

\section{J RG M}

Jørg Mørland (f. 1941) er professor emeritus ved Institutt for klinisk medisin, Universitetet i Oslo, dr.med. og spesialist i klinisk farmakologi. Han arbeider som fagdirektør/seniorforsker ved Område for helsedata og digitalisering, Folkehelseinstituttet, og var tidligere direktør for det rettsmedisinske fagområdet ved samme institutt. Han er medlem av toksikologisk gruppe i Den rettsmedisinske kommisjon. Han har sakkyndige oppdrag for rettsvesenet vedrørende spørsmål knyttet til rusmidler og legemidler.

Forfatter har fylt ut ICMJE-skjemaet og oppgir følgende interessekonflikter: Han har mottatt honorar fra Den rettsmedisinske kommisjon, det norske rettsapparatet og politiet i forbindelse med saker der mulig akkumulering av THC har vært et tema.

\section{J RGEN G.BRAMNESS}

E-post: j.g.bramness@medisin.uio.no

Jørgen G. Bramness (f. 1962) er seniorforsker, dr.med. ved Nasjonal kompetansetjeneste for samtidig rusmisbruk og psykisk lidelse (N-ROP), Sykehuset Innlandet, Hamar, og spesialist i psykiatri. Han har tidligere vært direktør for Senter for rus og avhengighetsforskning (SERAF) ved Universitetet i Oslo. Forfatter har fylt ut ICMJE-skjemaet og oppgir ingen interessekonflikter.

Etter jevnlig bruk av mye cannabis kan man gjenfinne den psykoaktive substansen THC i blodet i mange dager. Dette kan ha konsekvenser for cannabisbruk og bilkjøring, enten cannabis brukes medisinsk eller i rushensikt.

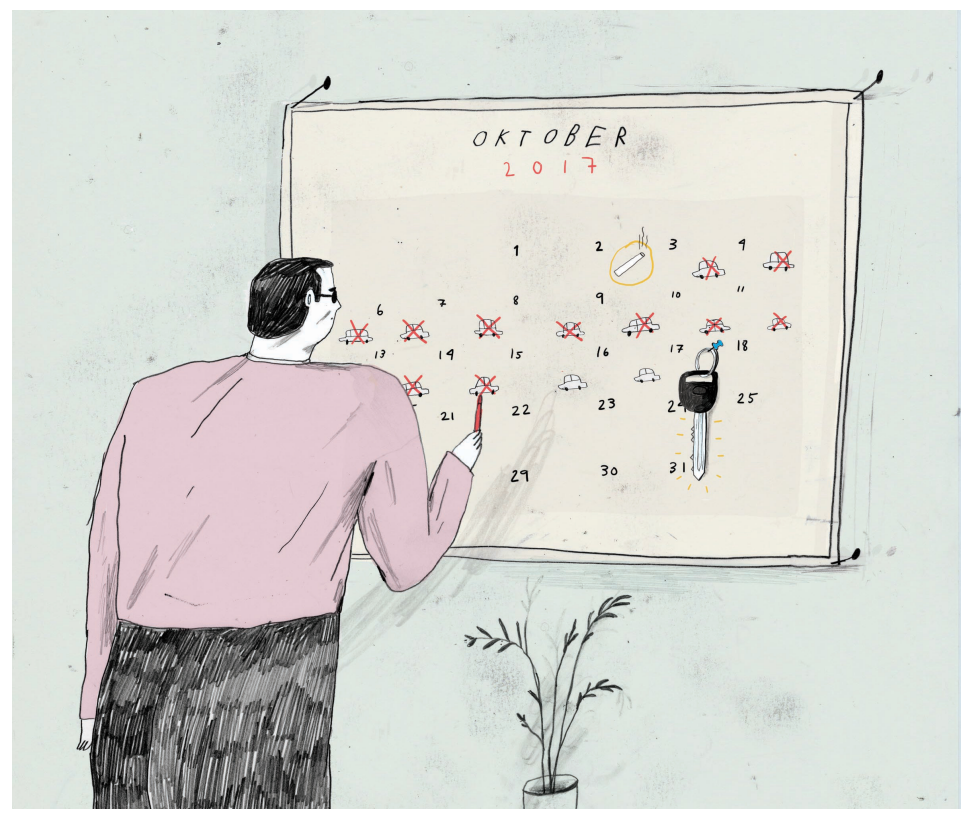


Rusmidler kan påvirke psykomotoriske ferdigheter så lenge de finnes i kroppen. Ny innsikt i farmakokinetikken til den viktigste psykoaktive substansen i cannabis, $\Delta \mathbf{9}$ tetrahydrocannabinol (THC), har endret vårt syn på hvor lenge cannabis kan ha en virkning. Dette kan ha betydning blant annet ved behandling av cannabisavhengighet og ved medisinsk bruk av cannabis. Hva slags råd skal leger gi pasienter om hvor lenge virkningene henger i? I forhold til å kjøre bil er spørsmålet relevant med tanke på edruelighetsbestemmelsen i vegtrafikkloven (§34) knyttet til førerkort og helsekravene i førerkortforskriften ( $\S \S 35$ og 36$)$.

Den viktigste substansen med hensyn til psykoaktiv påvirkning i cannabis er THC. De kognitive virkningene av cannabis som oppstår kort tid etter inntak, er større jo høyere THC-konsentrasjonen i blodet er $(1,2)$. Dette taler for at THC-konsentrasjonen i blodet reflekterer konsentrasjonen i hjernen, i alle fall i den akutte fasen, selv om man i noen studier antyder at THC-nivået kan være høyere og påvises lenger i hjernen enn i blodet (3).

\section{Farmakokinetikk}

Ved røyking av cannabis vil THC-konsentrasjonen i blodet stige raskt, for deretter å falle hurtig når man har avsluttet røykingen. Dette skyldes at THC elimineres (metaboliseres i lever og skilles ut), men først og fremst at stoffet fordeles til godt perfunderte organer som nyre, hjerte, hjerne, lever og lunger.

THC vil også fordeles langsomt til fettvev med lav perfusjon, men høy bindingskapasitet. I løpet av 4-6 timer faller THC-konsentrasjonen i blodet til lave konsentrasjoner (4), med en tilsynelatende eliminasjonshalveringstid $\left(T_{1 / 2}\right)$ på 1-2 timer (5). Ut fra dette har man inntil nylig trodd at den farmakologiske påvirkningen av cannabis bare varer i noen få timer.

Både annen eldre kunnskap og nyere forskning rokker imidlertid ved denne oppfatningen. En $T_{1 / 2}$ for THC på 1-2 døgn ble funnet allerede i 1970- og 8o-årene $(6,7)$, og ved hjelp av ultrasensitiv isotopteknikk fant noen forskere en gjennomsnittlig $T_{1 / 2}$ på over fire døgn (8). Vanlige farmakokinetiske prinsipper tilsier at et stoff kan påvises i blodet 4-5 ganger så lenge som $\mathrm{T}_{1 / 2}$, noe avhengig av analysemetodens sensitivitet. En studie fra 1988 viste at THC faktisk kan påvises i blodet i opptil $15 \mathrm{~d} ø g n$, men etter enkeltstående inntak er konsentrasjonen da så lav at den neppe er knyttet til noen virkning (9). Den lange påvisningstiden og den lange $T_{1 / 2}$ kan forklares med at THC blir redistribuert fra fettvev tilbake til blodet i denne terminale fasen (9). Dette er i overensstemmelse med at THC kan påvises i fettvev i opptil fire uker etter et større inntak (10).

Forskningsinteressen rundt cannabispåvirkning har handlet om de tydelige virkningene som er til stede de nærmeste timene etter et enkeltinntak. Svakere virkninger som eventuelt måtte foreligge på senere tidspunkt der THC-konsentrasjonen var vanskelig å måle uten tilgang på avanserte analysemetoder, ble ansett som mindre interessante. De eldre farmakokinetiske funnene synes derfor å ha blitt glemt, inntil relativt nye studier av personer som bruker svært mye cannabis, ble utført (11-13). Om man inntar cannabis på nytt før det er gått 4-5 ganger $T_{1 / 2}$ vil det uvegerlig føre til en viss akkumulering av THC. Den lange $\mathrm{T}_{1 / 2}$ for THC gir derfor store muligheter for omfattende akkumulering av THC, som blir mer uttalt jo hyppigere stoffet inntas. Når THC redistribueres, vil da man kunne få betydelige THC-mengder i blodet over tid. THC-konsentrasjoner som er tilstrekkelige til å gi psykomotorisk påvirkning og nedsatt kognisjon, er blitt målt i bortimot 10-15 (11-13) døgn og har vært påvisbare helt opptil 30 døgn $(11,12)$ etter store gjentatte inntak av cannabis.

Om man er påvirket i tiden etter gjentatte inntak, og hvor lenge en slik påvirkning varer i hvert enkelt tilfelle, er vanskelig å beregne uten detaljert kunnskap om bruksmønster for cannabis og THC-styrken i cannabisproduktet og derved mengden THC inntatt. 


\section{Bilkjøring og førerkort}

Man vurderer påvirkning i henhold til vegtrafikkloven på bakgrunn av

blodkonsentrasjonen av THC. Vi har vist at det er god overensstemmelse mellom utfall på kognitive og psykomotoriske ferdigheter og konsentrasjonen av THC i blodet (14-16).

Eksperimentelle undersøkelser viser at en THC-konsentrasjon i blodet på o,004 $\mu \mathrm{m}$ gir en påvirkning som grovt sett tilsvarer 0,2 promille alkohol i blodet (17), mens o,oo8 $\mu \mathrm{m}$ tilsvarer ca. o,4 promille (18).

Ved inntak av cannabis i rushensikt kommer den såkalte edruelighetsbestemmelsen i vegtrafikkloven (\$34) til anvendelse. Selv om bruken av cannabis er ulovlig, kan det hevdes at automatisk inndragelse av førerretten som følge av cannabisbruk som ikke er relatert til kjøring, er en dobbeltstraff. Det er antagelig usikkert om man administrativt kan frata personer retten til førerkort om de bare ruser seg en gang iblant, men venter lenge før de kjører bil og derfor ikke bryter vegtrafikklovens § 22 om kjøring i påvirket tilstand. Men dersom bruken innebærer at brukerne jevnlig har THC-konsentrasjoner over o,o04 um i blodet, som er straffbarhetsgrensen i henhold til vegtrafikkloven, vil det være rimelig at de fratas førerretten.

Bruksmønsteret er altså viktig når kjøreretten skal vurderes, men det er viktig å huske på at opplysninger om bruksfrekvens og THC-styrke kan være upresise. Kontrollmålinger av THC i blodet kan være en mulighet, men det er vanskelig å få tatt representative prøver. For å være 100 \% sikre på ikke å komme i konflikt med vegtrafikklovens § 22 om kjøring i påvirket tilstand, bør man ha minst én og kanskje helst to ukers opphold mellom inntakene for å unngå akkumulering av betydning. Det er opp til domstolen å avgjøre skikkethet i slike førerkortsaker, gjennom en avveining mellom det personlige ønsket om cannabisbruk på den ene siden og samfunnets interesser med trafikksikkerhet på den andre.

\section{Medisinsk behandling}

I Norge er det kun godkjent ett legemiddel som inneholder cannabisekstrakter (nabiksimoler, Sativex). Medikamentet brukes først og fremst til behandling av multippel sklerose (MS), men det har også vært forsøkt i for eksempel smertebehandling, I tillegg kan visse sykehusspesialister forskrive cannabisplanten som sådan (som ikke er et godkjent legemiddel) til behandling i spesielle tilfeller. Foreløpig er forskrivningen av Sativex moderat og forskrivningen av andre cannabisprodukter svært beskjeden.

Ved terapeutisk bruk av Sativex er det tvilsomt om man kommer opp i nivåer som vil påvirke kjøreevnen, selv ved jevnlig daglig terapeutisk bruk (19). Bruk av Sativex bør derfor etter vår mening kunne være forenlig med kravene til førerkort. Dette taler imot å opprettholde dagens strenge praksis om at førerretten inndras ved bruk av Sativex på andre indikasjoner enn multippel sklerose. Ved bruk av andre cannabisprodukter med høyere THC-innhold i medisinsk sammenheng bør THC-konsentrasjonene i blodet måles for å unngå konsentrasjoner over 0,004-0,008 um.

Sativex inneholder like deler av THC og cannabidiol (CBD). Noen andre cannabisprodukter kan brukes til medisinsk behandling, etter godkjenning av Statens legemiddelverk og Helsedirektoratet. Enkelte av disse produktene har et høyt innhold av THC, men inneholder lite cannabidiol. Cannabidiol har interessante medisinske egenskaper og gir antagelig liten eller ingen psykomotorisk påvirkning (20, 21). Mange opplever ren THC-påvirkning som ubehagelig og foretrekker medikamenter og faktisk også rusmidler som inneholder cannabidiol (22). Produkter som inneholder tilnærmet like mengder cannabidiol og THC, eller større mengde cannabidiol enn THC, bør etter vår mening vurderes, da disse muligens bedre kan kombineres med bilkjøring.

\section{Toleranse}

Et viktig spørsmål er hvorvidt jevnlige brukere av cannabis oppnår toleranse for THC- 
virkningen, slik man for eksempel ser hos smertepasienter som bruker opioider. Flere undersøkelser har antydet at dette også kan være tilfelle for THC $(23,24)$, men en helt ny undersøkelse viser ganske klart at fullstendig toleranse ikke utvikles (25), og at cannabis derfor må vurderes som andre vanedannende medisiner, for eksempel benzodiazepiner (26).

THC-påvirkning kan vare lenger enn man tidligere har antatt. For enkeltinntak snakker vi antagelig fortsatt om noen timer, men på grunn av akkumuleringseffekten vil hyppige gjentatte inntak, særlig av store mengder, kunne gi påvirkning i mange dager, og i ekstreme tilfeller i 1-2 uker. Denne nye kunnskapen gir noe støtte til den strenge fortolkningen av edruelighetsparagrafen i vegtrafikkloven. Samtidig burde ikke sjelden eller medisinsk bruk av i hvert fall munnsprayen Sativex komme i konflikt med edruelighetsparagrafen i vegtrafikkloven eller førerkortforskriftens helsekrav.

Til slutt vil vi anmerke at de kognitive langtidseffektene av cannabis, som kan vare i flere uker eller måneder etter siste bruk, antagelig ikke kan forklares av akkumuleringseffekter grunnet THCs lange halveringstid.

\section{LITTERATUR:}

1. Agurell S, Halldin M, Lindgren JE et al. Pharmacokinetics and metabolism of delta 1tetrahydrocannabinol and other cannabinoids with emphasis on man. Pharmacol Rev 1986; 38: 21 - 43. [PubMed]

2. Hunault CC, Mensinga TT, Böcker KB et al. Cognitive and psychomotor effects in males after smoking a combination of tobacco and cannabis containing up to $69 \mathrm{mg}$ delta-9tetrahydrocannabinol (THC). Psychopharmacology (Berl) 2009; 204: 85 - 94. [PubMed][CrossRef]

3. Mura P, Kintz P, Dumestre V et al. THC can be detected in brain while absent in blood. J Anal Toxicol 2005; 29: 842 - 3. [PubMed][CrossRef]

4. Hartman RL, Brown TL, Milavetz G et al. Effect of blood collection time on measured deltagtetrahydrocannabinol concentrations: implications for driving interpretation and drug policy. Clin Chem 2016; 62:367-77. [PubMed][CrossRef]

5. Toennes SW, Ramaekers JG, Theunissen EL et al. Comparison of cannabinoid pharmacokinetic properties in occasional and heavy users smoking a marijuana or placebo joint. J Anal Toxicol 2008; 32 : 470 - 7. [PubMed][CrossRef]

6. Wall ME, Sadler BM, Brine D et al. Metabolism, disposition, and kinetics of delta-9tetrahydrocannabinol in men and women. Clin Pharmacol Ther 1983; 34:352 - 63. [PubMed][CrossRef]

7. Lemberger L. Tetrahydrocannabinol metabolism in man. Drug Metab Dispos 1973; 1: 461 - 8.

[PubMed]

8. Johansson E, Halldin MM, Agurell S et al. Terminal elimination plasma half-life of delta 1tetrahydrocannabinol (delta 1-THC) in heavy users of marijuana. Eur J Clin Pharmacol 1989; 37: 273 - 7. [PubMed][CrossRef]

9. Johansson E, Agurell S, Hollister LE et al. Prolonged apparent half-life of delta 1-

tetrahydrocannabinol in plasma of chronic marijuana users. J Pharm Pharmacol 1988; 40:374- 5 . [PubMed][CrossRef]

10. Johansson E, Norén K, Sjövall J et al. Determination of delta 1-tetrahydrocannabinol in human fat biopsies from marihuana users by gas chromatography-mass spectrometry. Biomed Chromatogr 1989; 3:35-8. [PubMed][CrossRef]

11. Bergamaschi MM, Karschner EL, Goodwin RS et al. Impact of prolonged cannabinoid excretion in chronic daily cannabis smokers' blood on per se drugged driving laws. Clin Chem 2013; 59: 519 - 26. [PubMed][CrossRef]

12. Karschner EL, Swortwood MJ, Hirvonen J et al. Extended plasma cannabinoid excretion in chronic frequent cannabis smokers during sustained abstinence and correlation with psychomotor performance. Drug Test Anal 2016; 8: 682 - 9. [PubMed][CrossRef] 
13. Odell MS, Frei MY, Gerostamoulos D et al. Residual cannabis levels in blood, urine and oral fluid following heavy cannabis use. Forensic Sci Int 2015; 249: 173 - 8o. [PubMed][CrossRef]

14. Bramness JG, Khiabani HZ, Mørland J. Impairment due to cannabis and ethanol: clinical signs and additive effects. Addiction 2010; 105: 1080 - 7. [PubMed][CrossRef]

15. Khiabani HZ, Bramness JG, Bjørneboe A et al. Relationship between THC concentration in blood and impairment in apprehended drivers. Traffic Inj Prev 2006; 7: 111 - 6. [PubMed][CrossRef]

16. Høiseth G, Berg-Hansen GO, Øiestad AM et al. Impairment due to alcohol, tetrahydrocannabinol, and benzodiazepines in impaired drivers compared to experimental studies. Traffic Inj Prev 2017; 18: 244-50. [PubMed][CrossRef]

17. Vindenes $V$, Jordbru D, Knapskog AB et al. Impairment based legislative limits for driving under the influence of non-alcohol drugs in Norway. Forensic Sci Int 2012; 219: 1 - 11. [PubMed][CrossRef]

18. Grotenhermen F, Leson G, Berghaus G et al. Developing limits for driving under cannabis. Addiction 2007; 102:1910 - 7. [PubMed][CrossRef]

19. Indorato F, Liberto A, Ledda $\mathrm{C}$ et al. The therapeutic use of cannabinoids: Forensic aspects. Forensic Sci Int 2016; 265: 200 -3. [PubMed][CrossRef]

20. Bergamaschi MM, Queiroz RH, Zuardi AW et al. Safety and side effects of cannabidiol, a Cannabis sativa constituent. Curr Drug Saf 2011; 6: 237 - 49. [PubMed][CrossRef]

21. Havig SM, Høiseth G, Strand MC et al. THC and CBD in blood samples and seizures in Norway: Does CBD affect THC-induced impairment in apprehended subjects? Forensic Sci Int 2017; 276:12 - 7 . [PubMed][CrossRef]

22. Brunt TM, van Genugten M, Höner-Snoeken K et al. Therapeutic satisfaction and subjective effects of different strains of pharmaceutical-grade cannabis. J Clin Psychopharmacol 2014;34:344 - 9. [PubMed][CrossRef]

23. Ramaekers JG, Kauert G, Theunissen EL et al. Neurocognitive performance during acute THC intoxication in heavy and occasional cannabis users. J Psychopharmacol 20o9; 23: 266 - 77. [PubMed][CrossRef]

24. Hart CL, Ilan AB, Gevins A et al. Neurophysiological and cognitive effects of smoked marijuana in frequent users. Pharmacol Biochem Behav 2010; 96:333 - 41. [PubMed][CrossRef]

25. Ramaekers JG, van Wel JH, Spronk DB et al. Cannabis and tolerance: acute drug impairment as a function of cannabis use history. Sci Rep 2016; 6: 26843. [PubMed][CrossRef]

26. Willems IA, Gorgels WJ, Oude Voshaar RC et al. Tolerance to benzodiazepines among long-term users in primary care. Fam Pract 2013; 30: 404 - 10. [PubMed][CrossRef]

Publisert: 30. oktober 2017. Tidsskr Nor Legeforen. DOI: 10.4045/tidsskr.17.0429

Mottatt 10.5.2017, første revisjon innsendt 6.8.2017, godkjent 15.9.2017.

(C) Tidsskrift for Den norske legeforening 2020. Lastet ned fra tidsskriftet.no 